\title{
A prospective MRI study of left ventricular iron and function in non-trasfusion-dependent thalassemia intermedia patients treated with desferrioxamine
}

\author{
Antonella Meloni ${ }^{1 *}$, Mari Giovanna Neri ${ }^{1}$, Chiara Tudisca ${ }^{2}$, Elisabetta Chiodi ${ }^{3}$, Antonino Vallone ${ }^{4}$, \\ Daniele De Marchi ${ }^{1}$, Roberta Renni ${ }^{5}$, Carmelo Fidone ${ }^{6}$, Vincenzo Positano ${ }^{1}$, Alessia Pepe ${ }^{1}$
}

From 18th Annual SCMR Scientific Sessions

Nice, France. 4-7 February 2015

\section{Background}

In thalassemia intermedia (TI) patients no observational study prospectively evaluated in the real life the efficacy of the desferrioxamine (DFO) therapy in removing or preventing myocardial iron overload. The efficacy endpoint of this study is represented by the changes in cardiac $\mathrm{T}^{*}$ values and left ventricular (LV) function parameters in non-transfusion dependent (NTD) TI patients after 18 months of desferrioxamine therapy.

\section{Methods}

Among the 325 TI patients enrolled in the MIOT (Myocardial Iron Overload in Thalassemia) network, we selected 129 TI patients NTD. We considered 29 patients who had been received DFO alone between the two MRI scans. Cardiac iron overload was assessed by the multislice multiecho T2* technique. LV function parameters were quantified by cine SSFP sequences. Myocardial fibrosis was evaluated by late gadolinium enhancement (LGE) acquisitions.

\section{Results}

Mean age was $39.69 \pm 8.12$ years and $14(48.3 \%)$ patients were females. Patients started regular chelation therapy at a mean age of $21.92 \pm 15.89$ years. The mean administered dosage of DFO via subcutaneous route was 38.46 $\pm 10.27 \mathrm{mg} / \mathrm{kg}$ body weight on $3.32 \pm 1.54$ days/week. The percentage of patients with excellent/good levels of compliance to the chelation treatment was $82.1 \%$.
At baseline only one patient showed cardiac iron overload (global heart T2* $=15.23 \mathrm{~ms}$ ) but he recovered at the FU (global heart T2 $2^{*}=26.93 \mathrm{~ms}$ ). All patients without cardiac iron maintained the same status at the follow-up (FU).

Due mainly to technical reasons, LV function was assesses at both baseline and FU MRIs in 24 patients. At baseline all patients had a normal LV ejection fraction (EF) and 4 of them showed a reduced LV ejection fraction (LVEF) at the FU. The changes between the two MRIs in LV volumes and mass indexed by the body surface area as well in EF were not significant.

No movement abnormalities were detected at the baseline MRI while at the FU one patients showed ipokinesia in basal and mid inferoseptal LV wall.

For 21 patients the presence of myocardial fibrosis was investigated at both baseline and FU MRIs, and this subgroup was considered. Three (14.3\%) patients had myocardial fibrosis at the baseline, all with a non ischemic pattern.

At the FU two new occurrences of non-ischemic myocardial fibrosis were detected.

\section{Conclusions}

In this small population of sporadically or non transfused TI patients, the DFO therapy showed $100 \%$ efficacy in maintaining a normal global heart $\mathrm{T} 2 *$ value but it did not prevent the worsening of the LV function and the occurrence of new myocardial fibrosis. 


\section{Funding}

The MIOT project receives "no-profit support" from industrial sponsorships (Chiesi Farmaceutici S.p.A. and ApoPharma Inc.).

\section{Authors' details}

${ }^{1}$ CMR Unit, Fondazione G. Monasterio CNR-Regione Toscana, Pisa, Italy.

${ }^{2}$ Dipartimento di Radiologia, Policlinico "Paolo Giaccone", Palermo, Italy.

${ }^{3}$ Servizio Radiologia Ospedaliera-Universitaria, Arcispedale "S. Anna", Ferrara, Italy. "Istituto di Radiologia, Az. Osp. "Garibaldi" Presidio Ospedaliero Nesima, Catania, Italy. ${ }^{5}$ Day Hospital, Ospedale Civile "F. Ferrari", Casarano, Italy. ${ }^{6}$ U.O.S. di Microcitemia, Az. Osp. Civile, O.M.P.A. di Ragusa, Ragusa, Italy.

Published: 3 February 2015

doi:10.1186/1532-429X-17-S1-P339

Cite this article as: Meloni et al:: A prospective MRI study of left ventricular iron and function in non-trasfusion-dependent thalassemia intermedia patients treated with desferrioxamine. Journal of

Cardiovascular Magnetic Resonance 2015 17(Suppl 1):P339.

\section{Submit your next manuscript to BioMed Central} and take full advantage of:

- Convenient online submission

- Thorough peer review

- No space constraints or color figure charges

- Immediate publication on acceptance

- Inclusion in PubMed, CAS, Scopus and Google Scholar

- Research which is freely available for redistribution

Submit your manuscript at www.biomedcentral.com/submit
C Biomed Central 